\title{
A Biomedical Informatics Perspective on Human Factors - How Human Factors Influence Information Technology Adoption
}

\author{
R. Meyer, Section Editor for the IMIA Yearbook Section on Human Factors \\ Department of imaging and medical informatics, Geneva University Hospitals, Geneva, Switzerland
}

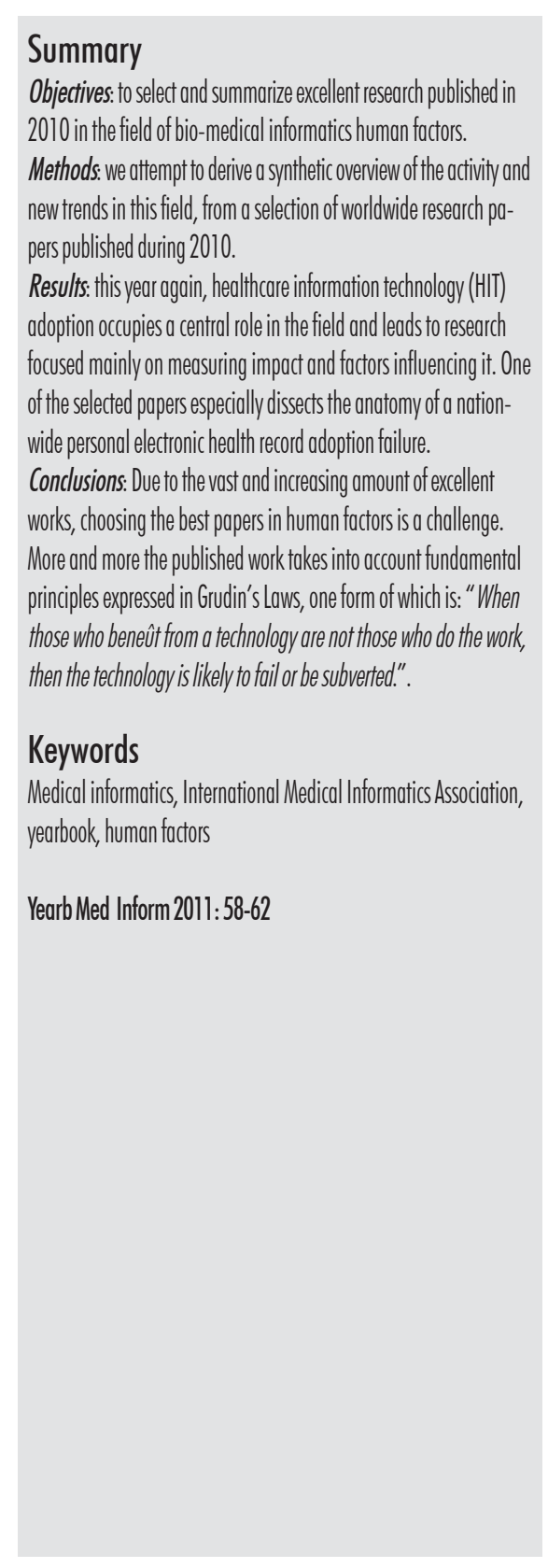

\section{Introduction}

There is accumulating evidence that HIT deployment improve quality of care and patient safety in most situations [18]. But the adoption of HIT is still slow [9-12] and the financials aspects of this reluctance, in a post-crisis context, are certainly not the main moderator, since research showed that high level HIT investments can bring value to hospitals [13]. Although some papers show that HIT may not always be reliable enough, it is not considered a major cause of non-adoption [14-15]. The explanation of slow adoption could be found in the 2009 National Research Council report [16] emphasizing the cognitive support importance that any healthcare information system (HIS) should provide to its users including care providers, patients and families. In a meaningful use context [17], disrespecting this conclusion could explain many HIT failures and misuses [18-23]. This year's selection directly echoes these considerations.

\section{Best Paper Selection}

The five papers selected this year, clearly address different aspects of the HIT adoption metrics and issues and how this adoption could become successful, or not... On the aspects of quality, Farah Magrabi [24] analyzes patient safety incidents associated with computer use as a starting point for the development of a classification. In the field of HIT adoption, Jean-Marc Palm [25] proposes the ITPAM model, which analyzes the relationships between post-adoption beliefs such as compatibility, perceived usefulness, ease of use, and user support, with confirmation of expectations and user satisfaction. In a post-adoption analysis, Trisha Greenhalgh [26] analyses the adoption failure of HealthSpace, an internet accessible personal electronic health record. Kai Zheng [27] proposes an almost ethnologic study of the behavior toward adoption of new technologies. His conclusion on the way to select innovation champions will certainly help a lot of project management teams and not only in the HIT field. Last but not least, Ben Tzion [28] presents a set of misconceptions that hinder the adoption of HIT. One could add yet another fallacy, the ,bookshelf fallacy" which is the general trend to consider/construct HIT as a big bookshelf holding vast amounts of wellorganized and easy to reach electronic health records (EHR) instead of structuring it as a component of a sociomedico-technical network.

\section{Conclusion and Outlook}

The selection illustrates three main aspects of the human factors needed for HIS acceptance: variability, agility, complexity. Variability, because the unified theory of the acceptance and 
use of technology describes four pillars: performance expectancy (perceived usefulness), effort expectancy (perceived ease of use), facilitating conditions, and social contagion (including direct persuasion and peer comparison); in addition to four moderating variables: gender, age, experience, and voluntariness of use [29-30]. In the HIS context, one could add the „type of work" variable according to Jean Marc Palm's [25] results stating that for physicians, the compatibility of IT with their clinical processes is more crucial for their satisfaction, whereas, for nurses perceived CIS ease of use seems more relevant. Agility, because many parts of healthcare delivery are complex and nonlinear [28]. In many clinical settings, multiple patients are managed simultaneously, with care providers repeatedly switching among sets of goals and tasks, continuously reprioritizing and replanning their work. HIS designed for single users, or for users doing discrete tasks in isolated sessions, are misconceived. [28]. HIS should be designed according to the new health professionals' teamspatients-families collaboration paradigm (each of them having different considerations, mental models and information needs). Complexity, because understanding what would help people in their work is not as simple as asking them what they want [31], a common approach. What clinicians say they want may be limited by their own understanding of the complexity of their work or even their design vocabulary. Thus, simply asking clinicians or any end-user, for that matter - what they want and giving it to them is not a wise approach [28]. What clinicians want and what will actually improve their work may be quite different. Thus the necessity of including human factors engineers and workflow specialists in all HIT project teams [32]. This selection of paper confirms again that positive user experience is the sine qua non condition to accept to do their job efficiently in an electronic healthcare information system [33]. In the US,

Table 1 Best paper selection of articles for the IMIA Yearbook of Medical Informatics 2011 in the section 'Human Factors'. The articles are listed in alphabetical order of the first author's surname.

\begin{tabular}{l} 
Section \\
Human Factors \\
\hline - Greenhalgh T, Hinder S, Stramer K, Bratan T, Russell J. Adoption, non-adoption, and abandonment of a personal electronic health \\
record: case study of HealthSpace. BMJ 2010;341:c5814. \\
- Karsh B-T, Weinger MB, Abbott PA, Wears RL. Health information technology: fallacies and sober realities. J Am Med Inform Assoc \\
2010; 17:617-23. \\
- Magrabi F, Ong M-S, Runciman W, Coiera E. An analysis of computer-related patient safety incidents to inform the development of a \\
classification. J Am Med Inform Assoc 2010;17:663-70. \\
- Palm J-M, Dart T, Dupuis I, Leneveut L, Degoulet P. Clinical Information System Post-Adoption Evaluation at the Georges Pompidou \\
University Hospital. AMIA 2010 Symposium Proceedings: 582-6. \\
- Zheng K, Padman R, Krackhardt D, Johnson MP, Diamond HS. Social networks and physician adoption of electronic health records: \\
insights from an empirical study. J Am Med Inform Assoc 2010; 17:328-36.
\end{tabular}

the Strategic Health IT Advanced Research Project (SHARP) on cognitive informatics and decision making in healthcare, received a major funding by the Office of the National Coordinator $(\mathrm{ONC})$. ONC is supporting innovative research to address well-documented problems that impede the adoption of health IT. The knowledge generated and innovations created from this program may accelerate progress toward the design of safe and effective healthcare information systems.

\section{Acknowledgement}

I acknowledge the support of Martina Hutter and the reviewers in the selection process of this section.

\section{References:}

1. Ash JS, Bates DW. Factors and forces affecting EHR system adoption: report of a 2004 ACMI discussion. J Am Med Inform Assoc 2005; 12(1):8-12.

2. Bates DW, Leape LL, Cullen DJ, Laird N, Petersen LA, Teich JM, et al. Effect of computerized physician order entry and a team intervention on prevention of serious medication errors. JAMA 1998;280:1311-16.

3. Chaudhry B, Wang J, Wu S, Maglione M, Mojica W, Roth E, et al. Systematic review: Impact of health information technology on quality, efficiency, and costs of medical care. Ann Intern Med 2006;144:742-52.

4. Devine EB, Hansen RN, Wilson-Norton JL, Lawless NM, Fisk AW, Blough DK, et al. The impact of computerized provider order entry on medication errors in a multispecialty group practice. JAm Med
Inform Assoc 2010;17:78-84.

5. King WJ, Paice N, Rangrej J, Forestell GJ, Swartz R. The effect of computerized physician order entry on medication errors and adverse drug events in pediatric inpatients. Pediatrics 2003;112:506-9.

6. Mekhjian HS, Kumar RR, Kuehn L, Bentley TD, Teater P, Thomas A, et al. Immediate benefits realized following implementation of physician order entry at an academic medical center. J Am Med Inform Assoc 2002;9:529-39.

7. Poon EG, Keohane CA, Yoon CS, Ditmore M, Bane A, Levtzion-Korach O, et al. Effect of barcode technology on the safety of medication administration. N Engl J Med 2010;362:1698-707.

8. Teich JM, et al. Effects of computerized physician order entry on prescribing practices. Arch Intern Med 2000;160(18):2741-7.

9. DesRoches CM, Campbell EG, Rao SR, Donelan K, Ferris TG, Jha A, et al. Electronic health records in ambulatory care, a national survey of physicians. N Engl J Med 2008;359:50-60.

10. Furukawa MF, Raghu TS, Spaulding TJ, Vinze A. Adoption of health information technology for medication safety in U.S. Hospitals, 2006. Health Aff(Millwood) 2008;27:865-75.

11. Jha AK, DesRoches CM, Campbell EG, Donelan K, Rao SR, Ferris TG, et al. Use of electronic health records in U.S. hospitals. N Engl J Med 2009;360:1628-38.

12. Pedersen CA, Gumpper KF. ASHP national survey on informatics: Assessment of the adoption and use of pharmacy informatics in US hospitals2007. Am J Health Syst Pharm 2008;65:224464.

13. Meyer R, Degoulet P. Choosing the right amount of healthcare information technologies investments. Int J Med Inform 2010 Apr;79(4):225-31. doi:10.1016/j.ijmedinf.2010.01.001

14. Linder JA, Ma J, Bates DW, Middleton B, Stafford RS. Electronic health record use and the quality of ambulatory care in the United States. Arch Intern Med 2007;167:1400-5.

15. Zhou L, Soran CS, Jenter CA, Volk LA, Orav EJ, Bates DW, et al The relationship between electronic health record use and quality of care over 
time. J Am Med Inform Assoc 2009;16:457-64.

16. Stead WW, Lin HS, editors. Computational Technology for Effective Health Care: Immediate Steps and Strategic Directions. Washington DC: National Academies Press; 2009.

17. US Department of Health and Human Services. Final rule on meaningful use. http:/edocket. access.gpo.gov/2010/pdf/2010-17207.pdf (accessed april 2011).

18. Ash JS, Sittig DF, Dykstra R, Campbell E, Guappone K. The unintended consequences of computerized provider order entry: Findings from a mixed methods exploration. Int J Med Inform 2009;78(Suppl 1):S69-76.

19. Koppel R, Metlay JP, Cohen A, Abaluck B, Localio AR, Kimmel SE, et al. Role of computerized physician order entry systems in facilitating medication errors. J Am Med Inform Assoc 2005;293:1197-203.

20. Koppel R, Wetterneck T, Telles JL, Karsh BT. Workarounds to barcode medication administration systems: occurrences, causes and threats to patient safety. J Am Med Inform Assoc 2008;15:408-28.

21. Nebeker JR, Hoffman JM, Weir CR, Bennett CL, Hurdle JF.. High rates of adverse drug events in a highly computerized hospital. Arch Intern Med 205;165:1111-16.

22. Peute LW, Aarts J, Bakker PJ, Jaspers MW. Anatomy of a failure: A sociotechnical evaluation of a laboratory physician order entry system implementation. Int J Med Inform 2010 Apr; 79(4):e58-70.

23. Wears RL, Cook RI, Perry SJ. Automation, interaction, complexity, and failure: A case study. Reliability Engineering \& System Safety 2006; 91:1494-501.

24. Magrabi F, Ong MS, Runciman W, Coiera E. An analysis of computer-related patient safety incidents to inform the development of a classification. J Am Med Inform Assoc 2010;17:663-70.

25. Palm JM, Dart T, Dupuis I, Leneveut L, Degoulet P. Clinical Information System Post-Adoption Evaluation at the Georges Pompidou University Hospital. AMIA 2010 Symposium Proceedings: 582-6.

26. Greenhalgh T, Hinder S, Stramer K, Bratan T, Russell J. Adoption, non-adoption, and abandonment of a personal electronic health record: case study of HealthSpace. BMJ 2010;341:c5814.

27. Zheng K, Padman R, Krackhardt D, Johnson MP, Diamond HS. Social networks and physician adoption of electronic health records: insights from an empirical study. J Am Med Inform Assoc 2010;17:328-36.

28. Karsh BT, Weinger MB, Abbott PA, Wears RL. Health information technology: fallacies and sober realities. J Am Med Inform Assoc 2010; 17:617-23.

29. Venkatesh V, Morris MG, Davis GB, Davis FD. User acceptance of information technology: toward a unified view. MIS Quart 2003;27:425e78.

30. Homans GC. The human group. New York: Harcourt Brace; 1950.

31. Andre AD, Wickens CD. When users want what's not best for them. Ergon Des 1995:10-4.

32. Diaper D, Stanton N, editors. The Handbook of Task Analysis for Human-Computer Interaction.
Mahwah, NJ: CRC Press, Lawrence Erlbaum Associates; 2003.

33. Meyer R. A Bio-Medical Informatics Perspective on Human Factors. Findings from the Yearbook 2009 Section on Human Factors. Yearb Med Inform 2010:106-9.

34. US Department of Health and Human Services. Strategic Health IT Advanced Research Projects (SHARP) Program. http://healthit.hhs.gov/ (accessed in May 2011).

\section{Appendix: Content Summary of Selected Best Papers for the IMIA Yearbook 2011, Section Human Factors*}

\section{Greenhalgh T, Hinder S, Stramer K, Bratan T, Russell J \\ Adoption, non-adoption, and abandonment of a personal electronic health record: case study of HealthSpace \\ BMJ 2010;341:55814}

In this work the United Kingdom authors evaluate the policy making process, implementation by National Health Service (NHS) organizations, and patients' and careers' experiences of efforts to introduce an internet accessible personal electronic health record (HealthSpace) in a public sector healthcare system. They use a mixed method and a multilevel case study focusing on the basic HealthSpace technology (available throughout England) and the advanced version (available only in a few localities). They choose to evaluate statistics on invitations sent and the number of accounts created. They also conduct interviews and ethnographic observation of patients and professionals. They consider macro and micro influences on both adoption and nonadoption of innovations with a sociotechnical approach, and the principles of critical discourse analysis. Between

\footnotetext{
* The complete papers can be accessed in the Yearbook's full electronic version, provided that permission has been granted by the copyright holder(s).
}

2007 and October 2010, 172950 people opened a basic HealthSpace account. $0.13 \%$ of those invited opened an advanced account, compared with 5 to $10 \%$ of the population anticipated in the original business case. Overall, patients perceived HealthSpace as neither useful nor easy to use and its functionality aligned poorly with their expectations and self-management practices. Those who used email-style messaging were positive about its benefits, but enthusiasm beyond three early adopter clinicians was low, and fewer than 100 of 30000 patients expressed interest. The hopes that HealthSpace would lead to empowered patients, personalized care, lower NHS costs, better data quality, and improved health literacy were not realized over the three year evaluation period. This paper illustrates the facts that personal electronic health records have a great chance to be abandoned or not adopted if they don't align closely with:

- People's attitudes;

- Self-management practices;

- Identified information needs;

- The wider care package (including organizational routines and incentive structures for clinicians).

\section{Karsh B-T, Weinger MB, Abbott PA, Wears RL Health information technology: fallacies and sober realities}

\section{J Am Med Inform Assoc 2010; 17:617-23}

The authors form USA and UK base their paper on the fact that the rate of adoption of health information technology (HIT) is low, and that HIT effects on quality of care (or costs) is still controversial. They propose that the failure of HIT adoption and HIT efficacy stems primarily from a series of fallacies about this technology. They expose 12 of them:

1. The 'bad apple' fallacy derived from the fact that it is widely believed that many healthcare problems are due primarily to human (especially clinician and middle manager) shortcomings. 
2. The 'learned intermediary' fallacy is the consequence of the 'learned intermediary' doctrine, the idea that HIT risks are negligible because the human alone ultimately makes the decision.

3. The 'messy desk' fallacy acknowledging that much of the motivation for HIT stems from the belief that something is fundamentally wrong with existing clinical work, that it is too messy and disorganized.

4. The 'sit-stay fallacy' comes from the fact that computers are very good at repeatedly doing whatever they were told to do, just like a welltrained animal (ie, 'sit-stay').

5. The 'father knows best' fallacy due to the fact that HIT has been sold as a solution to healthcare's quality and efûciency problems, most of the beneûts of current HIT systems accrue to entities upstream from direct patient care processes: hospital administrators, quality improvement professionals, payers, regulators, and the government.

6. The 'ûeld of dreams' fallacy suggests that if you provide HIT to clinicians, they will gladly use it, and use it as the designer intended. This fallacy is further reinforced by the belief that clinicians should rely on HIT because computers are, after all, smarter than humans.

7. The 'risk free' fallacy where many designers and policymakers believe that the risks of HIT are minor and easily manageable.

8. The 'one size fits all fallacy' is a major issue because HIT cannot be designed as if there is always a single user, such as a doctor, working with a single patient.

9. The 'we can go paperless' fallacy is widely spread but taking the data elements in a paper-based healthcare system and computerizing them is unlikely to create an efûcient and effective paperless system.

10. The 'HIT is not a device' fallacy (which is an off-shoot of the risk free fallacy) is the belief that HIT can be created and deployed with- out the same level of oversight as medical devices.

11. The "no one else understands healthcare' fallacy. Teams of wellintentioned clinicians and software engineers may believe that understanding of clinical processes coupled with clever programming can solve the challenges facing healthcare. But such teams typically will not have the requisite breadth and depth of theories, tools, and ideas to develop robust and usable systems.

12. The 'use equals success' fallacy where equating HIT usage with design success can be misleading and may promulgate inappropriate policies to improve use.

\section{Magrabi F, Ong M-S, Runciman W, Coiera E An analysis of computer-related patient safety incidents to inform the development of a classification}

\section{J Am Med Inform Assoc 2010;17:663-70}

This paper analyzes patient safety incidents associated with computer use as a starting point for the development of a classification of the problems reported by health professionals. A voluntary incident reporting database across one Australian state was built to retrieve all the incidents and a subset $(25 \%)$ was analyzed to identify the categories for classification. The submitted incidents have been independently and manually classified by coders. To identify contributing factors the authors also analyzed the free text descriptions accompanying the submissions. Whenever available, time of day, consequences, and medical specialty involved were examined. A search of 42616 incidents from 2003 to 2005 yielded 99 incidents describing 117 problems. They developed a classification including 32 types of computer use problems grouped into information input, transfer, output and general technical. Information input problems and information output problems correspond to errors in entering and retrieving infor- mation, and information transfer problems correspond to communication and coordination. Overall, $55 \%$ of problems were machine-related and $45 \%$ were attributed to human-computer interaction. Delays in initiating and completing clinical tasks were a major consequence of machine related problems whereas rework was a major consequence of human-computer interaction problems. While $38 \%$ of the incidents were reported to have a noticeable consequence but no harm, 34\% had no noticeable consequence. The authors conclude that evidence-based approaches to designing safer user interfaces are needed and must focus on features for the safe entry and retrieval of clinical information, and support users in detecting and correcting errors and malfunctions.

\section{Palm J-M, Dart T, Dupuis I, Leneveut L, Degoulet $P$ \\ Clinical Information System Post-Adoption \\ Evaluation at the Georges Pompidou University Hospital \\ AMIA 2010 Symposium Proceedings: 582-6}

This paper is based on the postulate that the integration of information technology (IT) into clinical processes must be analyzed and evaluated during the different phases of deployment of a clinical information system (i.e., preadoption, installation, and post-adoption), in order to improve their quality and effectiveness. For health care providers that have adopted IT to support their clinical processes it is essential, in post-adoption settings, to analyze the relationships between acceptability factors after successful IT implementation. The authors have used an expectationconfirmation model (called ITPAM) that analyzes the relationships between post-adoption beliefs such as, compatibility, perceived usefulness, ease of use, and user support, with confirmation of expectations and user satisfaction. Their results for the groups of physicians and nurses that replied to the survey $(n=312)$ suggest that health profes- 
sional satisfaction is mainly determined by the quality of user support, ease of use, confirmation of expectations, usefulness, and compatibility. The best predictor of physician satisfaction seems to be the compatibility of IT with their clinical processes whereas user support and perceived ease of use were determinant for nurses. Confirmation of expectations had an impact on postadoption expectation and user's satisfaction, and confirms its importance for HIT evaluation studies.

\section{Zheng K, Padman R, Krackhardt D, Johnson MP, Diamond HS \\ Social networks and physician adoption of electronic health records: insights from an empirical study}

\section{J Am Med Inform Assoc 2010;17:328-36}

This paper studies how social interactions influence physician adoption of an electronic health records (EHR) system. The work is based on social influence theories (an association of social contagion theory and technology acceptance theories) postulating that people are neither born with beliefs or behavior, nor are beliefs or behavior developed in isolation. Their formation and evolution occur primarily through social interactions as people compare their own beliefs or behavior with those of others, in particular, similar others. A social network survey was used to delineate the structure of social interactions among 40 residents and 15 attending physicians in an ambulatory primary care practice. Social network analysis was then applied to relate the interaction structures to individual physicians' utilization rates of an EHR system. The social network survey assessed three distinct types of interaction structures:

- Professional network based on consultation on patient care-related matters;

- Friendship network based on personal intimacy;

- Perceived influence network based on a person's perception of how other people have affected her intention to adopt the EHR system.

EHR utilization rates were measured as the proportion of patient visits in which sentinel use events consisting of patient data documentation or retrieval activities were recorded. The usage data were collected over a time period of 14 months from computer-recorded audit trail logs. Their results show that neither the professional nor the perceived influence network is correlated with EHR usage. The structure of the friendship network significantly influenced individual physicians' adoption of the EHR system. Residents who occupied similar social positions in the friendship network shared similar EHR utilization rates. In other words, residents who had personal friends in common tended to develop comparable levels of EHR adoption. Their main conclusion is that it is certainly a better strategy to choose an innovation promoter - or a physician champion among the popular physicians than the opinion leaders.

Correspondence to:

Dr. Rodolphe Meyer, MD, PhD

University Hospitals of Geneva

Department of Medico Economic Analysis

Geneva, Switzerland

Tel: +41 223726285

Fax: +41 796762445

E-mail: rodolphe.meyer@hcuge.ch 